\title{
Effect of small-sided handball game on aerobic capacity and repeated sprint ability of male handball players
}

\author{
Balasubramanian CHITTIBABU
}

Department of Physical Education and Sports Sciences, Annamalai university, Annamalainagar, Chidambaram, 608 002, Tamilnadu, India (e-mail: b.chitti@hotmail.com).

\begin{abstract}
The purpose of this study was to determine the effects of four and eight weeks small-sided handball game on aerobic capacity and repeated sprint ability of male handball players. Sixteen (16) male university handball players volunteered to act as subjects and were randomly assigned to small-sided handball game group (SSHG) and control group (CG). Small-sided handball game was administered three days in a week for eight weeks. Subjects were measured on aerobic capacity, total sprint time and fatigue index on three occasions first before administration of training as pre-test, after four weeks of training as mid test and after eight weeks of training as post-test. A two-way repeated measure ANOVA with last factor repeated revealed that aerobic capacity, total sprint time and fatigue index improved $(p<0.05)$. Aerobic capacity showed an improvement of $4.75 \%$ after four weeks and $8.83 \% \%$ after eight weeks of small-sided handball game training in male handball players. Similarly, total sprint time and fatigue index also decreased $4.19 \%$ and $34.9 \%$ only after eight weeks of training but after four weeks no changes is observed. This study shows that small-sided handball game (4 vs. 4) is effective in improving aerobic capacity in four and eight weeks of training but total sprint time and fatigue index elicited changes only after eight weeks.
\end{abstract}

Keywords: Aerobic capacity, fatigue index, handball, small-sided game, university.

\section{INTRODUCTION}

Handball performance is highly dependent upon a combination of technical, physical and tactical skills of players, among which physical fitness plays a vital role during a handball match. Modern game structured with fast pace which keep the players on toe to sprint, fake, throw and jump repeatedly without getting fatigue (20). During a handball match players perform an intermittent activities at high intensity that require a combination of aerobic and anaerobic fitness $(8,9,16,29,38)$. After inception of handball in Olympics, it gradually improved the players' physical fitness, physique, physiological and psychological characteristics. The intensity of the game has been improved as a result of new training methodologies.

Today, handball players require greater aerobic capacity and repeated sprint ability. The ability to perform (and recover from) repeated high intensity activities over a prolonged period of time coupled with a good aerobic capacity is deemed essential physiological requirements for success in handball. The game handball composed of repeated sprint of players for fast breaks and quick counter attacks which require great aerobic capacity. The players with greater aerobic capacity tend to show lower fatigue index which show negative correlation in handball players (14). The players who perform the most sprints require high levels of aerobic capacity to aid recovery after high-intensity bouts of activity. It is required for handball players in different position and its importance cannot be neglected since all the field players in the court gets equal chance for fast break and quick counterattacks. The role of the repeated sprint ability is greater and which determines the result of the match. Fatigue index indicates the rate at which power output declines which show the athletes anaerobic endurance. The continuous method and interval methods which are widely used by the coaches to enhance the performance of players but the scenario have completely changed.

Optimizing training programs for athletes is important because failure to properly condition a team which results in a poor performance and often defeat. The coaches presently use various conditioning skills among, skill based conditioning 
is prescribed to all level players, because this type offers many benefits. One of the benefits of implying this type of training is the combination of sports specific skills and fitness. According to Bompa (7) maximum benefits are achieved when the training stimuli are similar to competitive demands. In order to reproduce the physical, technical and tactical requirements of real match play $(23,31,37)$, coaches often use small-sided game (SSG) in their training programs. SSG which are very popular in soccer, basketball, handball and rugby, where players use smaller play area and less number of participants during small-sided games, each player comes into contact with the ball and deals with common game situations more often (10). These situations require good technical skills such as passing, dribbling, feinting and shooting as well as tactical skills such as running without the ball, unmarking and cooperation with other players. The advantages of this training ensure the players to perform optimally during a game. Earlier studies had showed that elite players for 7 to 12 weeks at 90-95\% HRmax during pre and in season resulted in improvement in aerobic capacity and repeated sprint ability $(11,22,25,26,27)$

This study attempts to find the effect of smallsided handball game for short duration on university male handball players. Therefore, the aim of this study is to assess the effect of four and eight weeks small-sided handball game on aerobic capacity and fatigue index of male handball players.

\section{MATERIAL \& METHODS}

\section{Subjects}

Sixteen (16) university male handball players were selected from Department of Physical Education and Sports Sciences, Annamalai University, Chidambaram, Tamilnadu, India. The selected subjects represented Annamalai University in Indian University Competition. The selected handball players age $22.12 \pm 3.22$ years; height 174.50 $\pm 7.83 \mathrm{~cm}$ and weight $65.62 \pm 7.79 \mathrm{~kg}$. These players have minimum of eight years of playing experience and gave willingness to take part in the study. The general characteristics of the participants in smallsided handball game group and control group are shown in Table 1.

\section{Study Design}

The subjects were randomly assigned to two groups. Group $1(\mathrm{n}=8)$ performed small-sided handball game training while Group $2(n=8)$ served as control group. In the present study repeated measure design was employed. Testing of each group was performed on three occasions first before administration of training as pre-test, after four weeks of training as mid test and after eight weeks of training as post-test.

Table 1. General characteristics (mean \pm standard deviation) of the small-sided handball game group and control group.

$\begin{array}{lcc}\text { Variables } & \text { SSHG } & \text { CG } \\ & & \\ \text { Age (years) } & 22.87 \pm 2.35 & 21.37 \pm 3.92 \\ \text { Height }(\mathrm{cm}) & 171.56 \pm 7.01 & 170.43 \pm 8.93 \\ \text { Weight }(\mathrm{kg}) & 65.87 \pm 8.09 & 65.37 \pm 8.03 \\ \text { Percent body fat }(\%) & 8.18 \pm 4.16 & 8.92 \pm 2.26 \\ \text { Lean body mass }(\mathrm{kg}) & 60.17 \pm 6.18 & 60.98 \pm 13.72\end{array}$

\section{Variable and Test}

\section{Yo-Yo intermittent recovery test level II}

The aerobic capacity of handball players was measured through Yo-Yo intermittent recovery test level II. The players were administered with ten minutes of warming up. Then players were asked to line up in front of twenty meter marked area with cones. The tester instructs the subjects to run half way and return to the starting point when the sound signal produced from music player. The tester keeps recording the distance covered by the players. We used formula for estimation of $\mathrm{VO}_{2} \max =$ distance in meter $\times 0.0136+45.3(3)$.

\section{Total sprint time and fatigue index}

To evaluate the fatigue index all subjects completed multiple sprint running protocols, which consisted of $7 \times 30 \mathrm{~m}$ sprints repeated at $25 \mathrm{~s}$ intervals (Rebelo et al. 1998). The subjects were given verbal signal provided a 10 second countdown to start of each sprint and subjects were verbally encouraged to give maximal effort. All timing was recorded manually using a stop watch by establishing both tester and equipment reliability. Total sprint time was calculated by summing up all the seven sprint times presented in seconds. Fatigue index was calculated from sprint times using the following formulae: Fatigue $=\{$ (slowest sprint fastest sprint) / fastest sprint $\} \times 100$.

\section{Small-sided handball game}

Small-sided handball training will be performed 3 days in a week for eight weeks. They perform 4 repetitions of high intensity game for 4 minutes at 90 to $95 \%$ of HRmax and 4 minutes of active recovery with intensity of 60 to $65 \%$ of HRmax they performed handball passing drills. The 
players were strapped with polar heart rate monitor and exercise heart rate were fixed and if they perform below or above the fixed range it produces the beep sound alert the players.

\section{Rules}

The coaches encourage the players to perform activity of high intensity. In this training 4 players play against 4 players at high intensity in a standard handball court of $40 \times 20$ meters. In order to play at high intensity we simplified handball rules in order to avoid interruption in the game and increase the exercise load. The rule modifications are a) dribbling and defence contacts are not allowed, b) walking, ball hitting below the knee of court player and illegal dribbles were not penalised, c) goal keeper throw was granted immediately after a goal, d) goal will not be validated unless all four players present in the opponents court at the time of goal, e) ball will be replaced immediately when it is thrown out of the playing area, f) throw in administered immediately without delay, g) penalty throw, substitutions, warning and disqualifications were not granted, g) goalkeepers were instructed to remain inside goalkeeper area during the entire duration. In the present study training was administered only for four court players but not for goalkeeper.

\section{Statistical Analyses}

A two-way repeated measure ANOVA with last factor repeated was applied to examine the difference between the groups (SSHG and CG), testing conditions (Pre, Mid and Post test) and interaction (Groups $\times$ Testing conditions). When interaction is significant simple effect was applied and followed by Scheffe $S$ post hoc test was applied and in the case of all statistically significant outcomes, the meaningfulness of the differences between the means was expressed with reference to the effect size (ES, Cohen's d). All the statistical tests were calculated using the statistical package for the social science (SPSS) for windows (Version 16). The level of statistical significance was set at $\mathrm{p}<0.05$.

\section{RESULTS}

The following section details the results pertaining to aerobic capacity, total sprint time and fatigue index of handball players. The mean changes in aerobic capacity, total sprint time and fatigue index before training, after four weeks of training and after eight weeks of training in SSHG and CG (Figure 1, 2 \& 3).

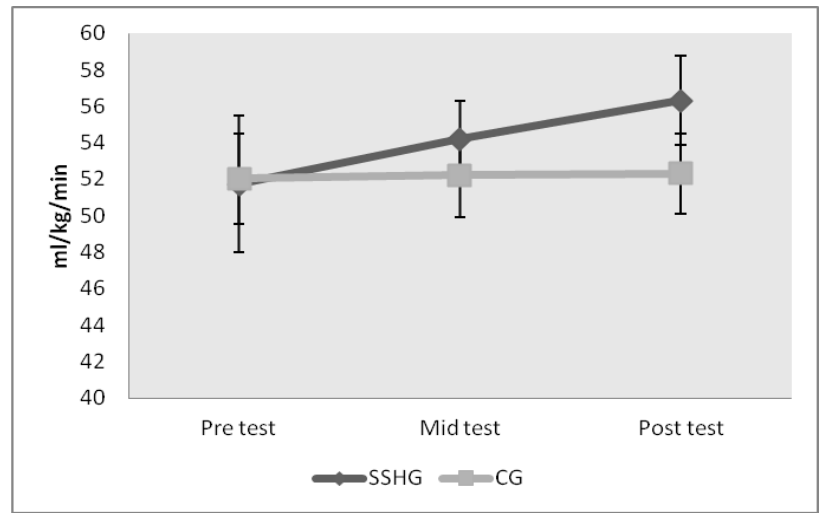

Figure 1. Mean and standard deviation of SSHG and CG on aerobic capacity.

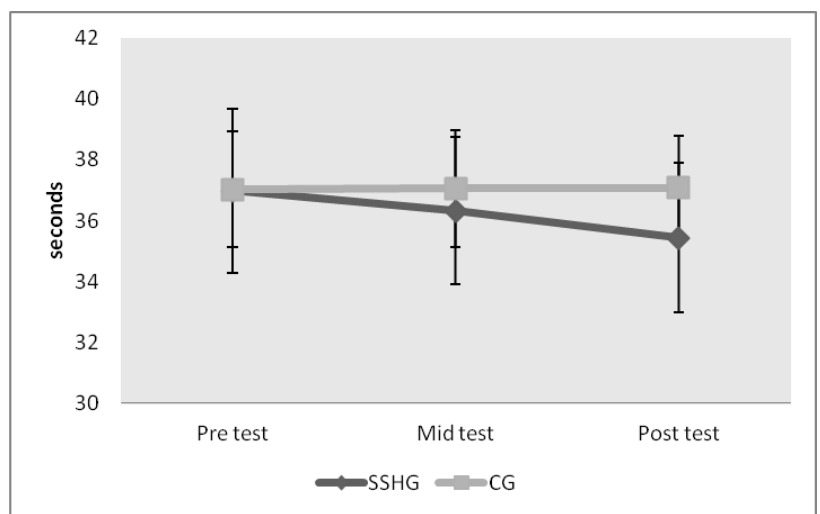

Figure 2. Mean and standard deviation of SSHG and CG on total sprint time.

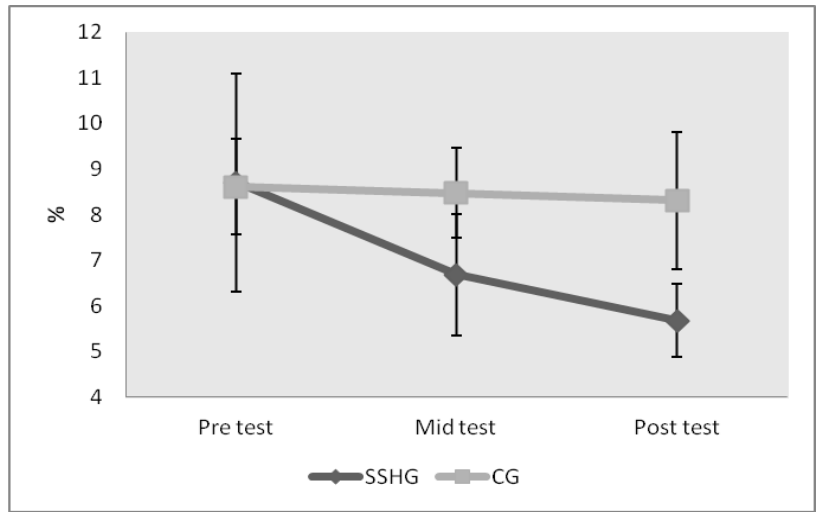

Figure 3. Mean and standard deviation of SSHG and CG on fatigue index.

\section{Aerobic Capacity}

The two - way repeated measures ANOVA revealed a significant main effect for groups $(F(1$, $14)=8.39, p=0.000)$, different testing conditions $(F$ $(2,28)=65.40, p=0.000)$ and interaction effect $(F(2$, $28)=51.36, p=0.000)$. Table 2 which clearly show a significant differences between the groups after four and eight weeks of training, where SSHG had greater aerobic capacity than CG. The Scheffe S post hoc test within SSHG displayed 4.75\% (MD - 2.46 $\mathrm{ml} / \mathrm{kg} / \mathrm{min} \&$ Cohen's $d=0.84$ ) improvement after 
four weeks of training and 8.83\% (MD - 4.57 $\mathrm{ml} / \mathrm{kg} / \mathrm{min} \&$ Cohen's $d=1.47$ ) after eight weeks of small-sided handball game training in male handball players. This shows that small-sided handball game has large effect and which confirm that aerobic capacity improved after four and eight weeks of small-sided handball game.

\section{Total Sprint Time}

The two - way repeated measures ANOVA revealed no significant main effect for groups $(F(1$, $14)=0.550, p=0.471)$, different testing conditions $(F$ $(2,28)=9.583, p=0.001)$ and interaction effect $(F(2$, $28)=10.51, p=0.000$ ). Table 2 which clearly show a significant differences between the groups after four and eight weeks of training, where SSHG had lower total sprint time than CG. The Scheffe $S$ post hoc test within SSHG displayed decrease in total sprint time $(4.19 \%$ \& Cohen's $d=1.48)$ after eight weeks of small-sided handball game training in male handball players. This shows that small-sided handball game has large effect of changes in total sprint time after eight weeks of small-sided handball game.

\section{Fatigue Index}

The two - way repeated measures ANOVA revealed a significant main effect for groups ( $F(1$, $14)=4.76, \mathrm{p}=0.047)$, different testing conditions $(\mathrm{F}$ $(2,28)=21.70, \mathrm{p}=0.000)$ and interaction effect $(\mathrm{F}(2$, $28)=14.78, p=0.000)$. Table 2 which clearly show a significant differences between the groups after four and eight weeks of training, where SSHG had lower fatigue index than CG. The Scheffe $S$ post hoc test within SSHG displayed decrease in fatigue index (MD: $3.04 \%$ \& Cohen's $d=1.90$ ) after eight weeks of small-sided handball game training in male handball players. This shows that small-sided handball game has large effect of changes in fatigue index after eight weeks of small-sided handball game.

\section{DISCUSSION}

\section{Aerobic Capacity}

The primary finding of this study showed that four and eight weeks of small-sided handball game (4 versus 4 ) significantly improved aerobic capacity of university male handball players. In the present study skill based conditioning games which constitutes both handball specific skills and fitness. The intensity, duration and frequency are key determinant to improve aerobic capacity. Earlier, Chittibabu (13) in his study showed that handball specific repeated sprint training for eight weeks is more effective in increasing aerobic capacity of men handball players. The training load adopted in repeated - sprint training with game specific which resulted in $11.79 \%$ of changes in aerobic capacity, however, the improvement in the present study is less. The four minutes of high intensity game and active recovery for four minutes $(4 \times 4)$ facilitate to improve aerobic capacity of male handball players. Similarly, Helgerud et al. (21) proved that aerobic power has been shown to improve in soccer players. Similarly, Coutts et al. (15) clearly state that game based training improves both fitness and skill. The present study clearly shows that four weeks of training resulted in $4.75 \%$ of improvement and $8.83 \%$ after eight weeks of training. This clearly shows that short duration of this training can improve aerobic capacity of male handball players. The improvement in aerobic capacity after the handball specific aerobic training protocol is consistent with the findings of previous studies in soccer (21) and rugby (19). The changes in aerobic capacity due to handball specific aerobic training may result in several changes in cardiovascular function, including increased maximal cardiac output, increased stroke volume, and reduced heart rate at rest and during submaximal exercise. The change in cardiovascular function with endurance training is resulted from an increase in maximal cardiac output, resulting primarily from improved stroke volume (1).

Table 2. Two - way repeated measure ANOVA and Simple effect of aerobic capacity and repeated sprint ability.

\begin{tabular}{|c|c|c|c|c|c|c|c|c|}
\hline \multirow{3}{*}{ Variables } & \multirow{3}{*}{$\begin{array}{l}\text { Groups } \\
\quad F\end{array}$} & \multirow{3}{*}{$\begin{array}{c}\text { Testing } \\
\text { conditions } \\
F\end{array}$} & \multirow{3}{*}{$\begin{array}{c}\text { Interaction } \\
\quad F\end{array}$} & \multicolumn{5}{|c|}{ Simple Effect } \\
\hline & & & & \multicolumn{3}{|c|}{ Difference between the groups at } & \multicolumn{2}{|c|}{$\begin{array}{l}\text { Difference at testing } \\
\text { conditions on }\end{array}$} \\
\hline & & & & Pre test & Mid test & Post test & SSHG & CG \\
\hline $\begin{array}{l}\text { Aerobic capacity } \\
(\mathrm{ml} / \mathrm{kg} / \mathrm{min})\end{array}$ & $8.39^{*}$ & $65.40^{*}$ & $51.36^{*}$ & 0.117 & $10.83^{*}$ & $36.16^{*}$ & $19.62 * \$$ & 0.089 \\
\hline RSA - Total sprint time (sec) & 0.550 & $9.58^{*}$ & $10.51^{*}$ & 0.002 & $9.03^{*}$ & $44.75^{*}$ & $20.09^{*} \#$ & 0.001 \\
\hline Fatigue index $(\%)$ & $4.76^{*}$ & $21.70^{*}$ & $14.78^{*}$ & 0.011 & $9.16^{*}$ & $19.07^{*}$ & $7.04^{* \#}$ & 0.125 \\
\hline
\end{tabular}

$* p<0.05$;

$\$=$ Scheffe S Post hoc test on aerobic capacity: Pre vs. Mid; Pre vs. Post; Mid vs. Post;

\# =Scheffe $S$ Post hoc test on total sprint time and fatigue index: Pre vs. Post 


\section{Total Sprint Time and Fatigue Index}

A key physiological requirement of game handball is the ability to repeatedly produce short, maximal effort activities with incomplete recovery (repeated sprint ability). During a handball match players run for fast break and returns back to stop quick counter attacks, which clearly show the requirement of repeated sprint ability. In the present study small-sided handball game training for eight weeks significantly decreased total sprint time and fatigue index by $4.19 \%$ and $34.9 \%$ respectively. Earlier Chittibabu (12) found a significant correlation between maximal oxygen consumption and fatigue index of male handball players. It states that handball players with greater maximal oxygen consumption had lower fatigue index. This clearly shows that repeated sprint ability require a greater aerobic capacity to improve recovery between repeated bouts of maximal sprinting $(5,32)$ is likely related to the ability to tolerate, remove, and buffer hydrogen ions $(\mathrm{H}+)$ from the working muscle (34) while efficiently restoring $\mathrm{PCr}$ and ATP stores from inorganic phosphates post exercise (6). Previous research has shown that the extent of $\mathrm{PCr}$ degradation and $\mathrm{H}+$ accumulation, which increases with repeated bouts of maximal exercise (2), is associated with muscular fatigue.

Additionally, athletes with greater $\mathrm{VO}_{2}$ max has been proposed to directly enhance faster lactate removal and $\mathrm{PCr}$ restoration, thus enhancing power and force recovery (Bassett et al. 1991); there should be some advantage because of an attenuated decrement in force in successive bouts. Though lactate was not measured during this investigation, it is safe to speculate that blood lactate can reach extremely high levels during exercise of this nature. Research has indicated that elevated $\mathrm{H}+$ concentration due to a high rate of lactate formation contributes to fatigue in various ways $(17,18,28,35)$, all of which lead to impaired force production. It is noted that enhanced aerobic enzyme concentrations and an increased mitochondrial surface area providing greater transport sites for pyruvate $(24,36)$, it is likely to enhance lactate removal. Therefore, it stands to reason that greater lactate clearance capability (which can only occur via oxidative means) should enhance performance on repeated sprint bouts and fatigue index. In the present study, onset of blood lactate accumulation and hydrogen ion concentration in the blood were not assessed which stands as a limitation and in future if it is assessed it will be more helpful in quantifying the result.
In Conclusion, the result from the present study suggests that small-sided handball game (4 vs. 4 ) is effective in improving aerobic capacity in four and eight weeks of training but RSA (total sprint time and fatigue index) elicited changes only after eight weeks. This suggests that smalls sided handball game training is efficient enough to run repeated sprints at high intensity during a match.

\section{ACKNOWLEDGEMENT}

I am thankful to Dr. G. Ravindran, Professor and Head, Department of Physical Education and Sports Sciences, Annamalai University for providing me an opportunity to conduct this study and emphasis special thanks to Ph.D. scholars, for assisting in collecting data. I am also great full to my students who took part in this study.

\section{REFERENCES}

1. Baechle TR, Earle RW. Essentials of Strength Training and Conditioning. 3rd ed., Champaign, IL: Human Kinetics, 2008, 127-128.

2. Balsom PD, Seger JY, Sjödin B, Ekblom B. Maximal intensity intermittent exercise: effect of recovery duration. International Journal of Sports Medicine, 1992; 13(7): 528-533.

3. Bangsbo J, Iaia FM, Krustrup P. The Yo-Yo intermittent recovery test: a useful tool for evaluation of physical performance in intermittent sports, Sports Medicine, 2008; 38(1): 37-51.

4. Bassett DR, Merrill PW, Nagle F, Agre JC, Sampedro R. Rate of decline in blood lactate after cycling exercise in endurancetrained and untrained subjects. J Appl Physol, 1991; 70: 18161820

5. Bogdanis GC, Nevill ME, Boobis LH, Lakomy HK. Contribution of phosphocreatine and aerobic metabolism to energy supply during repeated sprint exercise. J Appl Physiol, 1996; 80(3): 876-84.

6. Bogdanis GC, Nevill ME, Boobis LH, Lakomy HKA. Contribution of phosphocreatine and aerobic metabolism to energy supply during repeated sprint exercise. Journal of Applied Physiology, 1996; 80(3): 876-884.

7. Bompa T. Theory and methodology of training. Dubusque, Iowa: Kendall/Hunt, 1983.

8. Buchheit M, Laursen PB, Kuhnle J, Ruch D, Renaud C, Ahmaidi S. Game-based training in young elite handball players. Int J Sports Med, 2009; 30: 251-258.

9. Buchheit M, Lepretre PM, Behaegel AL, Millet GP, Cuvelier G, Ahmaidi S. Cardiorespiratory responses during running and sport specific exercises in handball players. J Sci Med Sport, 2009; 12: 399-405.

10. Capranica L, Tessitore A, Guidetti L, Figura F. Heart rate and match analysis in pre-pubescent soccer players. Journal of Sports Sciences, 2001; 19: 379-384.

11. Chamari K, Hachana Y, Kaouech F, Jeddi R, Moussa-Chamari I, Wisloff U. Endurance training and testing with the ball in young elite soccer players. Br J Sports Med, 2005; 39(1): 24-28. 
12. Chittibabu B. Comparison of repeated sprint ability and fatigue index among male handball players with respect to different playing position. International Journal of Physical Education Fitness and Sports, 2014; 3(1): 71-75.

13. Chittibabu B. Effect of handball specific repeated - sprin training on aerobic capacity of male handball players. International Journal of Physical Education, Fitness and Sports, 2013; 2(4): 4-7.

14. Chittibabu B. Estimation of relationship between maximal oxygen consumption and repeated sprint ability of male handball players. International Journal of Physical Education, Fitness and Sports, 2014; 3(2): 79-84.

15. Coutts AJ, Hill-Haas S, Moreira A, Aoki MS. Use of skillbased games in fitness development for team sports. Brazilian Journal of Sport and Exercise Research, 2010; 1(2): 108-111.

16. Delamarche P, Gratas A, Beillot J, Dassonville J, Rochcongar $\mathrm{P}$, Lessard Y. Extent of lactic anaerobic metabolism in handballers. Int J Sports Med, 1987; 8: 55-59.

17. Fitts RH. Cellular mechanisms of muscle fatigue. Physiol Reviews, 1994; 74: 49-94.

18. Fuchs F, Reddy V, Briggs FN. The interactions of cations with the calcium-binding site of troponin. Biochem Biophys Acta, 1970; 221: 407-409.

19. Gabbett T. Skill based conditioning games as an alternative to traditional conditioning for rugby league players. J Strength Cond Res, 2006; 20(2): 309-315.

20. Gorostiaga EM, Granados C, Ibáňez J, Izquierdo M Differences in physical fitness and throwing velocity among elite and amateur male handball players. Int J Sports Med, 2005; 26: 225-232

21. Helgerud JL, Engen C, Wisloff U, Hoff J. Aerobic endurance training improves soccer performance. Med Sci Sports Exerc 2001; 33(11): 1925-1931.

22. Hill-Haas S, Coutts AJ, Dawson BT, Rowsell GJ. Generic versus small-sided game training in soccer. Int J Sports Med, 2009; 30(9): 636-42.

23. Hoff J, Wisløff U, Engen LC, Kemi OJ, Helgerud J. Soccer specific aerobic endurance training. Brit J Sports Med, 2002; 36(3): 218-221.

24. Holloszy JO, Coyle EF. Adaptations of skeletal muscle to endurance exercise and their metabolic consequences. Journal of Applied Physiology Respiratory Environmental and Exercise Physiology, 1984; 56(4): 831-838.

25. Impellizzeri F, Marcora S, Castagna C, Reilly T, Sassi A, Iaia FM, Rampinini E. Physiological and performance effects of generic versus specific aerobic training in soccer players. Int J Sports Med, 2006; 27(6): 483-492.

26. Jensen J, Randers M, Krustrup P, Bangsbo J. Effect of additional in-season aerobic high-intensity drills on physical fitness of elite football players. J Sports Sci Med, 2007; 6(10): 79.

27. McMillan K, Helgerud J, Macdonald R, Hoff J. Physiological adaptations to soccer specific endurance training in professional youth soccer players. Br J Sports Med, 2005; 39(5): 273-277.

28. Powers SK, Howley ET. Exercise physiology: Theory and Applicationto Fitness and Performance (5th Edition), McGraw-Hill, New York, NY, USA, 2004.

29. Rannou F, Prioux J, Zouhal H, Gratas-Delamarche A Delamarche P. Physiological profile of handball players. J Sports Med Phys Fitness, 2001; 41: 349-353.

30. Rebelo N, Krustrup P, Soares J, Bangsbo J. Reduction in intense intermittent exercise performance during a soccer match. Journal of Sports Sciences, 1998; 16: 482-483.

31. Reilly $\mathrm{T}$, White C. Small-sided games as an alternative to interval-training for soccer players. J Sports Sci, 2004; 22: 559.

32. Riechman SE, Zoeller RF, Balasekaran G, Goss FL, Robertson RJ. Prediction of $2000 \mathrm{~m}$ indoor rowing performance using 30 s sprint and maximal oxygen uptake. J Sports Sci, 2002; 20(9): 681-7.

33. Sahlin K, Henriksson J. Buffer capacity and lactate accumulation in skeletalmuscle of trained and untrained men, Acta Physiologica Scandinavica, 1984; 122(3): 331-339.

34. Sahlin K, Henriksson J. Buffer capacity and lactate accumulation in skeletal muscle of trained and untrained men. Acta Physiologica Scandinavica, 1984; 122(3): 331-339.

35. Sahlin K. Metabolic factors in fatigue. Sports Med, 1992; 13: 99-107.

36. Saltin B, Rowell LB. Functional adaptations to physical activity and inactivity. Federation Proceedings, 1980; 39(5): 1506-1513.

37. Sassi R, Reilly T, Impellizzeri F. A comparison of small-sided games and interval training in elite professional soccer players. J Sports Sci, 2004; 22: 562.

38. Souhail H, Castagna C, Mohamed HY, Younes H, Chamari K. Direct validity of the Yo-Yo intermittent recovery test in young team handball players. J Strength Cond Res, 2010; 24: 465-470, 2010. 